\title{
Preparation and characterisation of protein concentrates from defatted kenaf seed.
}

\begin{abstract}
Two kenaf varieties QP3 and V36 were used to obtain protein concentrates. Proximate analysis, foaming, water and oil absorption properties were studied. Significant $(\mathrm{P}<0.05)$ differences were observed among the two varieties only in their content in oil and carbohydrates. The protein concentrate yield was $13.04 \%$ and $10.56 \%$, respectively. The two varieties showed significantly different $(\mathrm{P}<0.05)$ water and oil absorption capacities. QP3 showed higher foaming capacity than did V38, and it was increased with increasing salt and sugar concentration. Albumin was the main fraction representing 59.6\% and $66.1 \%$ in QP3 and V36 varieties, respectively, followed by globulin, which represented $22.6 \%$ and $19.1 \%$, respectively. The ratios of albumin, globulin, glutelin and prolamin were significantly different. Based on the data obtained from sodium dodecyl sulphate polyacrylamide gel electrophoresis, the main kenaf seed proteins present in the concentrates were five proteins with molecular weights ranging from 10 to 66 . $\mathrm{kDa}$. From differential scanning calorimetry data, QP3 and V36 protein concentrates had similar denaturation temperatures (82.6 and $81.8^{\circ} \mathrm{C}$, respectively).
\end{abstract}

Keyword: Differential scanning calorimetry; Foaming property; Hibiscus cannabinus; Oil absorption; Protein concentrate; Sodium dodecyl sulphatepolyacrylamide gel electrophoresis; Water absorption. 